\title{
ANTROPOLOGÍA
}

\section{¿ESTAMOS SOLOS ANTE LA MUERTE?}

\author{
$M^{a}$ Belén Martínez Cruz* \\ Javier Calatayud García**
}

Enfermera de la Unidad de Cuidados Paliativos*

Enfermero Urgencias**

Hospital General Universitario Gregorio Marañón (Madrid)

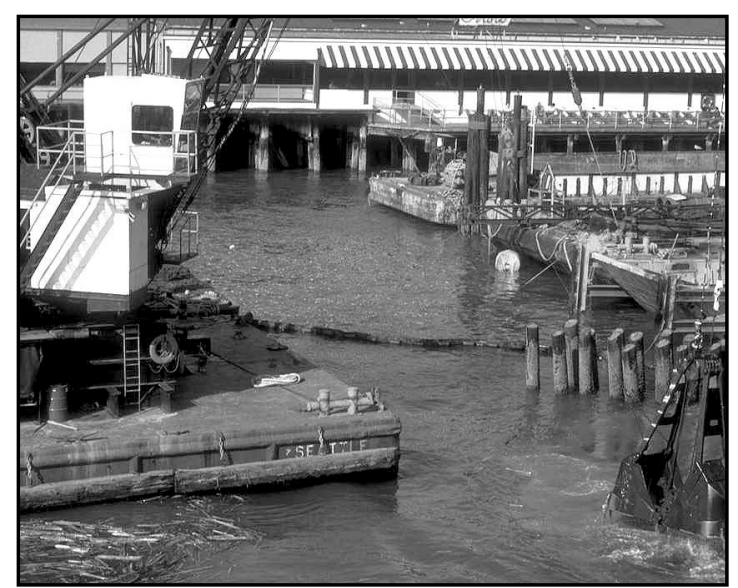

ARE WE ALONE BEFORE DEATH?

\section{ABSTRACT}

$\mathrm{F}$ lear and cultism towards death in western societies cause feelings of anguish and loneliness when something as natural as death approaches us. Hiding the truth to patients is quite common. The silence conspiracy is a fact between relatives and patients who see their life ending. For all that, it is worth asking: are we alone before death?

KEY WORDS: Death. Loneliness. Silence conspiracy. Right to information.

\section{RESUMEN}

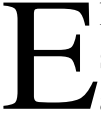
1 miedo y el ocultismo hacia la muerte en la sociedad occidental hacen que cuando se acerca algo natural como es el final de la vida aparezcan sentimientos de angustia y de soledad. El ocultar la verdad a un paciente en la actua- lidad es bastante habitual. La conspiración de silencio es un hecho entre la familia y el paciente que ve que su vida se le está escapando. Por todo ello cabe plantearse la pregunta ¿estamos solos ante la muerte?

PALABRAS CLAVE: Muerte. Soledad. Conspiración de silencio. Derecho a la información

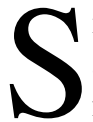
iempre había pensado en la muerte como algo lejano, tenebroso, algo que no se debía ni mencionar. Todo muy acorde con lo que pensamos la gran mayoría de las personas que habitamos este maravilloso mundo civilizado $\mathrm{y}$ desarrollado, el denominado de la "medicina moderna". A este mundo al que cada vez se le hace más cuesta arriba enfrentarse a algo tan natural como es el morir. Mundo que idolatramos, y nos creemos cada vez más, que es "cuasi perfecto". Hay que recordar que quizás sea la muerte la que nos ponga los pies en el suelo, ya que a otras cosas, muchos de nosotros nos hemos por desgracia habituado. La guerra ya no es tan cruel porque todos los días la tenemos en casa, en nuestra pantalla del televisor y nos queda lejos. El hambre del llamado por nosotros tercer mundo también está lejos, y nos consolamos con pensar que la culpa la tienen sus gobiernos. Pero hay algo que aunque queramos alejar de nuestras vidas está siempre presente, y más tarde o más temprano nos tocará de cerca, la muerte. Y mi pregunta es: ¿ESTAMOS SOLOS ANTE LA MUERTE?

Como enfermera de una unidad de Cuidados Paliativos considero que en muchas ocasiones así 
es. No desde el punto de vista físico, puesto que la gran mayoría de las muertes que yo he vivido con pacientes, siempre han estado acompañados. A lo que me refiero es a ese silencio que persiste incluso hasta el mismo momento. A esa soledad del paciente ante la muerte que se le avecina, y de la que no ha podido ni hablar durante su proceso, por que todos le decían: "...no digas esas cosas que todo va a salir bien". A esa conspiración de silencio, cada vez más habitual y que contrasta tanto con la obligación que tenía el médico de decir la verdad al enfermo en la Edad Media.

Actualmente el debate está centrado en la eutanasia, en su legalización. Pero, ¿no deberíamos antes discutir sobre el conocimiento de la verdad del paciente? Si ni siquiera somos capaces, a veces, de comunicarle que su evolución no es favorable, y que quizás su pronóstico se reduce a 3, 6 meses, o un año de vida. ¿Cómo queremos darle la opción de solicitar su muerte anticipada y a la carta?

La despedida era un acto fundamental del ceremonial del deceso durante la Edad Media, por tanto la información al paciente era un deber del médico, según un documento pontificio. Pero en la $2^{\mathrm{a}}$ mitad del s. XIX, se estimó conveniente ocultar al enfermo la gravedad de su estado para protegerle, manteniéndole aislado en un ambiente de falso optimismo, donde las decisiones más importantes se tomaban sin contar con él. Cuando el enfermo se daba cuenta de su situación, ya era demasiado tarde para que alguien se atreviera a decírselo, no solo para ahorrarle sufrimiento a él, sino también para evitárselo a sus allegados. Una situación bastante comparable con la que ocurre actualmente.

La Ley 41/2002, de 14 de Noviembre resalta el derecho a la información, el consentimiento informado y la intimidad de la información relativa a la salud de las personas. El Artículo 4 de esta Ley hace referencia al Derecho a la información asistencial:

1. Los pacientes tienen derecho a conocer, con motivo de cualquier actuación en el ámbito de su salud, toda la información disponible sobre la misma, salvando los supuestos exceptuados por la Ley. Además toda persona tiene derecho a que se respete su voluntad de no ser informado...

2. La información clínica forma parte de todas las actuaciones asistenciales, será verdadera, se comunicará al paciente de forma comprensible y adecuada a sus necesidades y le ayudará a tomar decisiones de acuerdo con su propia y libre voluntad.

3. El médico responsable del paciente le garantiza el cumplimiento de su derecho a la información. Los profesionales que le atiendan durante el proceso asistencial o le apliquen una técnica o un procedimiento concreto también serán responsables de informarle.

El Artículo 5 se refiere al titular del derecho a la información:

1. El titular del derecho a la información es el paciente. También serán informadas las personas vinculadas a él, en la medida que el paciente lo permita de manera expresa o tácita.

2. El paciente será informado, incluso en caso de incapacidad, de modo adecuado a sus posibilidades...

3. Cuando el paciente, según el criterio del médico que le asiste, carezca de capacidad para entender la información a causa de su estado físico o psíquico, la información se pondrá en conocimiento de las personas vinculadas a él por razones familiares o de hecho.

Además de los imperativos legales que ya existen, nunca deberíamos olvidar que, informar a un enfermo que tiene una dolencia mortal es, antes que nada, un acto incuestionablemente humano, por supuesto médico, ético y según lo anterior legal. Es cierto que es el médico y no otro profesional el responsable de dar la información sobre un diagnóstico y un pronóstico, pero los demás profesionales que forman parte del equipo asistencial no deberíamos eludir nuestra responsabilidad con actitudes evasivas ante las preguntas de un paciente.

La muerte siempre ha estado presente a lo largo de la historia de la humanidad, quizás sea ahora cuando queramos intentar borrarla de nuestras vidas y abogar por una inmortalidad inventada, que llegamos a creernos. Esta inmortalidad viene dada por los avances tecnológicos, por las vacunas que han erradicado enfermedades como la viruela, o los transplantes de órganos, o sin ir más lejos, algo que creemos que es tan normal como la existencia de la insulina, la cual es de una relativa juventud, 
tan solo cumple ahora 84 años. Por el gran arsenal farmacéutico del que podemos valernos los "ricos" de esta sociedad y que son capaces de cronificar nuestras enfermedades, hasta convertirnos en: "paciente de 80 años con pluripatología, HTA, diabetes, gonartrosis, insuficiencia mitral, Epoc..." Hace no tantos años esto sería incompatible con la vida.

Este es el precio que tenemos que pagar por todo lo que avanza nuestra sociedad, no estoy diciendo que esto no sea maravilloso, que sean grandes logros del ser humano, y que nos permitan vivir más años y relativamente bien; lo que quiero resaltar es, que todo esto nos hace olvidar que la muerte también forma parte de nuestras vidas. Que como el resto de mamíferos, nacemos, crecemos, envejecemos y morimos, pero se podrían distinguir tres diferencias:

El hombre es el único animal que sabe que envejece

El hombre es el único animal que sabe que ha de morir

El hombre es el único animal que le duele la vejez y le teme a la muerte

Lo que le crea problemas al hombre no es la muerte sino la existencia de ella

Solo el hombre está solo. Es que se sabe vivo y mortal. Es que siente huir - ese río del tiempo hacia la muerte -.

$$
\text { Blas de Otero "Lo eterno" }
$$

Así contestaba Antonio Gala a Jesús Quintero a la pregunta:

$$
\text { - ¿Usted viviría mil años? }
$$

- No viviría mil años porque me parece que la muerte no está mal pensada. La muerte da intensidad y vehemencia a la vida. La inmortalidad nos haría sentarnos, acomodarnos. Con mil años por delante, siempre diríamos: lo haré el siglo que viene, lo haré dentro de un par de siglos...

Solo la idea de plantearnos el ser inmortales creo que nos haría recapacitar sobre lo "bueno" que es el que la muerte exista. Pensemos en un mundo en el que no existiera, como el que inventó Turoldo en "La muerte del último teólogo", donde nos hace una hipótesis sobre una isla en la que la muerte no existe, sí el envejecimiento y la enfermedad. En este relato los protagonistas llegan a pedir suplicando el regreso de la muerte.

"Señor, mándanos la muerte, la gran muerte, la bella muerte, perdónanos si en algún tiempo nos hemos lamentado porque se moría, si no hemos sabido ser felices como tu querías, si no hemos comprendido; la muerte es la puerta de la salvación, la entrada a tu palacio; la vida es distancia , nos exilia a uno de otro, nos conduce al desierto..."

Elisabeth Kübler-Ross nos habla de la muerte como "...la culminación de la vida, el tránsito, la despedida antes de entrar en otro lugar; el fin antes de otro principio. La muerte es la gran transición."

Si tuviésemos todos tiempo de reflexionar, en este mundo repleto de estrés, prisas y úlceras de estómago, donde lo que prima es el ser el primero, el mejor y el más competitivo, nos daríamos cuenta que el ocultar la verdad, o parte de la verdad, o simplemente lo que las personas queremos saber acerca de lo que nos pasa, no es una buena praxis. No se muere mejor no sabiendo que se acerca el final. Esta es la conclusión que nos da la experiencia de los que trabajamos diariamente con la muerte cerca, con el llanto y la tristeza de los que han perdido a un ser querido, pero no le han dicho todo lo que querían, por ocultar lo que el paciente sabía desde hacía ya tiempo, y que él tampoco quiso contar, por no hacer sufrir a nadie.

Hay bastante diferencia entre estas frases que escuchamos a los familiares cuando ingresan en la unidad:

- "El/ella lo sabe todo sobre su enfermedad desde el principio así lo quiso y respetamos su decisión porque es su vida, desde entonces hemos hablado mucho y hemos solucionado temas pendientes..."

- "El/ella no sabe nada, y tampoco queremos que se entere, cuando nos pregunta sobre el tema le decimos que todo va a salir bien, que se curará pronto porque aquí hay muy buenos médicos." 
¿Mentiras piadosas para proteger? $\mathrm{O}_{i}$ miedo a enfrentarse a la realidad de la muerte?

Sería razonable meditar sobre estas cuestiones, sobre todo cuando estas "mentiras piadosas" provienen de un profesional.

La conspiración de silencio se define como "un acuerdo implícito o explícito de alterar la información al paciente por parte de los familiares, amigos y/o profesionales sanitarios con el fin de ocultarle el diagnóstico y/o pronóstico y/o gravedad de la situación”.

“ La comunicación puede que, en ocasiones, resulte difícil, pero la incomunicación lo es mucho más".

La experiencia indica que en la mayor parte de los casos, la comunicación de la verdad resulta beneficiosa y causa un profundo alivio si se ha sabido dar correctamente. No es una actitud razonable ni decir la cruda realidad sin contemplaciones, ni decir la mentira piadosa creando ese falso optimismo insostenible como si el enfermo hubiese perdido su facultad de entendimiento.

Conviene ir informando poco a poco respondiendo a las inquietudes, dejando siempre una salida a la esperanza, aunque sin mentir. Se trata de un arte que hay que saber desarrollar.
Apartemos por tanto las preocupaciones del día a día, y reflexionemos sobre las respuestas que damos a los pacientes y familiares, que dejan en nuestras manos toda su confianza.

\section{BIBLIOGRAFÍA:}

- Arranz P., Barbero J. J., Barreto P., Bayés R. (2003). Intervención emocional en cuidados paliativos Modelo y protocolos. Ariel Ciencias Médicas; Barcelona: 98

- BOE 15 noviembre (2002), núm. 274, (pág. 40126). Ley básica reguladora de la autonomía del paciente y de derechos y obligaciones en materia de información y documentación clínica.

- Gómez M. (1994). La comunicación en la relación de ayuda. Cuidados Paliativos e Intervención Psicosocial en enfermos terminales. ICEPSS Las Palmas de Gran Canaria: 267-278.

- Gómez M. (2000). Cómo dar las malas noticias en medicina. Arán; Madrid: 57

- Gómez M. (2003). La muerte familiar. Ars Moriendi. El problema de la muerte en la sociedad actual. Avances en cuidados paliativos. GAFOS; Las Palmas de Gran Canaria:3-29

- Quintero J. Gala A. (1999).Trece Noches. Planeta; Barcelona: 211.

- Kübler-Ross E. (2003). Los niños y la muerte. Luciérnaga, Sexta reimpresión; Barcelona: 11

- López E.,(1998), Perspectivas históricas sobre la muerte. Enfermería en Cuidados Paliativos. Panamericana. Madrid: 37.

- Toynbee A. (1977). El interés del hombre en la vida después de la muerte. En: Toynbee A., Koestler A. Et al eds. La vida después de la muerte. Edhasa, Barcelona: 25.

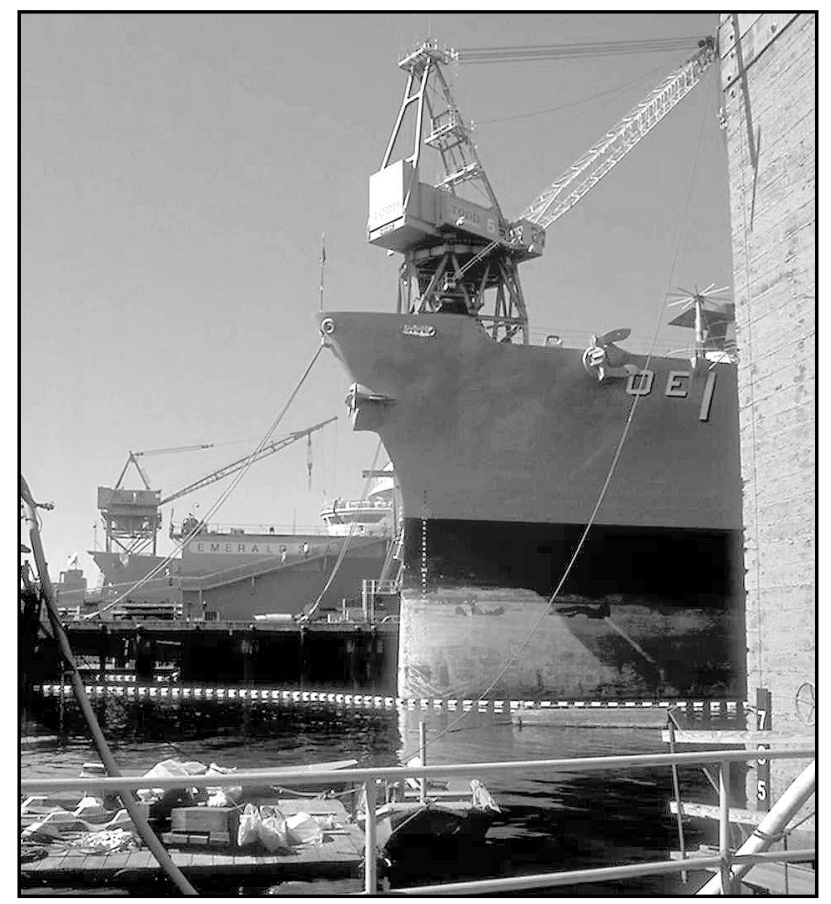

